\title{
Performance analysis of smart lighting control system for sustainable campus operation
}

\author{
Tunku Muhammad Nizar Tunku Mansur ${ }^{1 *}$, Rosnazri Ali $^{2}$, N. H. Baharudin ${ }^{3}$ and K. Ananda-Rao ${ }^{1}$ \\ Faculty of Electrical Engineering Technology, University Malaysia Perlis, Malaysia ${ }^{1}$ \\ Centre of Sustainable Campus and Energy Management, University Malaysia Perlis, Malaysia ${ }^{2}$ \\ Centre of Excellence for Renewable Energy (CERE), Universiti Malaysia Perlis, Malaysia ${ }^{3}$
}

Received: 17-November-2020; Revised: 23-January-2021; Accepted: 25-January-2021

(C2021 Tunku Muhammad Nizar Tunku Mansur et al. This is an open access article distributed under the Creative Commons Attribution (CC BY) License, which permits unrestricted use, distribution, and reproduction in any medium, provided the original work is properly cited.

\begin{abstract}
Global warming is a growing issue today due to the concerns of carbon emissions to the environment. Meanwhile, learning institutions such as university could play a significant role in promoting energy conservation and sustainable campus operations. The objective of this paper is to highlight the performance of smart lighting control system for restrooms where the project has been carried out at the Faculty of Electronic Engineering Technology, Universiti Malaysia Perlis. The methodology processes include the initial study and field measurement of the energy consumption for lighting system during pre-retrofit condition, design, and development of the lighting control system and lastly analysis of the designed system in post-retrofit condition after installation. On the overall, 58 motion sensors have been installed at 30 restrooms where the result shows that in average $77.5 \%$ of reduction in energy consumption per day for each restroom. This situation has given tremendous benefits to the university operation where the university could save $9377 \mathrm{kWh}$ per year and reduced RM 3423 from electricity bill per annum. In addition, this project also contributes to the environmental sustainability where the amount of electrical energy that has been successfully reduced is equivalent to $6508 \mathrm{~kg}$ of $\mathrm{CO}_{2}$ avoidance to the environment.
\end{abstract}

\section{Keywords}

Energy conservation, Energy efficiency, Lighting control system, Retrofitting, Sustainable campus.

\section{Introduction}

Energy conservation is a growing issue in today's world especially in controlling building's energy consumption [1]. This is due to the global warming issue caused by carbon emissions especially from the generation of energy from fossil fuels which is a major concern for the environment [2]. For Peninsular of Malaysia, the baseline $\mathrm{CO}_{2}$ for electricity generation is $0.694 \mathrm{tCO} 2 / \mathrm{MWh}$ based on study in 2014 [3]. Institution of higher learning such as university could play a significant role in reducing energy consumption and promoting energy efficiency and sustainability in its operation [4, 5]. For Universiti Malaysia Perlis (UniMAP) that is located at the northern part of the Peninsular Malaysia, its main campus consumed 14639 MWh of electricity in 2019. This amount of energy is enormous and needs attention from campus residents.

*Author for correspondence
Based-on the observation, lack of energy conservation practices and awareness on environmental sustainability are among the main causes. Recently, UniMAP has taken initiatives to plan and implement energy efficiency practices that focused on buildings at its main campus which is parts of university's sustainable campus program.

To reduce building energy consumption, retrofitting energy efficient technologies is preferable than reconstructing to improve building energy performance [6]. One of the essential steps in order to improving energy efficiency is by performing energy audit [7]. Conducting an energy audit and implementing its recommendation will resulting reduction of the energy consumption of the building hence lowering the electricity bill without compromising the comfort [8]. For educational buildings, internal lighting contributes considerable amount of energy consumption [9]. Therefore, the purpose of this paper is to highlight the performance 
of smart lighting control system for restrooms where the project was carried out at the Faculty of Electronic Engineering Technology, UniMAP.

The objectives of this paper are as follows:

1. To investigate the energy profile of the restrooms through energy audit.

2. To design and develop the lighting control system based on zone area as energy saving solution.

3. To monitor and evaluate the effectiveness of the designed lighting control system as energy saving solution.

This paper is organized in the following manner: Introduction and objectives of the research work are described in Section 1 while related literature reviews are presented in Section 2. Section 3 explained the methods involved while Section 4 presented the results and discussion. Lastly Section 5 summarized the conclusion.

\section{Literature review}

Various methods and approaches that could increase the energy efficiency in buildings have been studied by researchers. A research by [10] has investigated the technique of controlling light brightness with light dependent resistor (LDR) sensor and occupancy sensor such as passive infrared (PIR) sensor which will utilize the smart phone as one of the devices to control the system. A study by [11] has suggested that by replacing the fluorescent tube lamps with LED type will offer superior energy saving to an average $48.47 \%$ reduction in energy consumptions.

Control strategies related to the sensing-based has been reviewed by [12], which are occupancy and daylight based strategies which also included techniques of positioning the sensor, sensor technologies and assessment of energy usage. The conclusion was the occupancy pattern and building characteristics are the main factors contributing to higher energy savings of sensing-based strategies in commercial buildings and mixed strategy could produce up to $95 \%$ energy savings compared with other strategies. A research by [13] has proposed a street lighting control system to provide a reduction in power consumption by dimming the brightness of the lamps which could reduce monthly energy usage up to $40 \%$.

A comparative analysis has been carried out by [14] on day-light level-based strategies which are switching daylight and dimming daylight through software simulation for a hotel building. Their study has shown considerable decrease in the electricity usage can be achieved using daylight-based lighting control between 30-40\% energy saving. Another study by [15] has proposed an intelligent system that incorporate six lighting control operations for commercial and residential buildings. Based on experimental results, both switching and dimming control could decrease energy usage up to $68 \%$ during typical days.

A dimming control system of office lighting based by coordinating the access control system and the lighting control system has been proposed by [16] where the presence or absence of employee in a floor will determine the light dimming rate. Based on evaluation, the system could reduce about $25 \%$ power consumption of lighting in office. A research conducted by [17] has concluded that every lighting control technologies have their own respective contribution elements that will determine the success of energy efficiency project. Factors such as building's orientation, natural daylighting, building's orientation, type of task executed and occupant's comfort must be considered since it will affect the energy saving performance. A work by [18] has found the occupancy density is one of the contributing factors for university's building energy consumption. Therefore, a new approach in determining the Energy Efficiency Index (EEI) has been proposed by including this factor in the EEI calculation. Another approach is by controlling the air-conditioning unit where a study by has shown an average savings of $32 \%$ per day from microcontroller-based ACU controller [19]. A study from [20] has proposed implementation of solar PV system under the net energy metering (NEM) scheme for university buildings. From evaluation, energy reduction between a quarter to one million ringgit of annual electricity bill could be achieved by the university depending on the sizing capacity.

A walkthrough audit was conducted by [21] to determine the load consumption profile of the hostel buildings. Based on the audit report, up to $50 \%$ reduction of energy cost could be achieved by using energy efficient lamps with payback period less than 10 years. Another potential energy saving project has been studied by [22] for outdoor lighting applications including the roads, footpaths, and garden lights. As a result, $762 \mathrm{MWh}$ of electricity could be saved per year by implementing combination of retrofitting the lighting and dimming control systems. Another energy efficiency strategy has been proposed by [23] to improve the lighting performance of a service 
building at Rest and Service Area that continuously operates for 24 hours daily. Based on the simulation results, $17 \%$ of energy saving could be met by decreasing the overall time operation while another $49 \%$ reduction from daylight control dimming system. A research has been conducted by [24] to compare various types of lamps in terms of energy saving performance. Based on the analysis, smart LED bulb consumed the lowest electricity compared to halogen, CFL and LED, only when it is dimmed and is remotely controlled. Has proposed strategies aiming to improve energy efficiency at SharmElshiekh airport [25]. Based on the simulation, 57\% of lighting load could be reduced by using LED technology while up to $25 \%$ of monthly electricity usage could be saved by using fuzzy control system without affecting the comfort level of the occupants.

\section{Methods}

In this section, methodology procedures of the project have been discussed which include initial study and field measurement of the energy consumption for lighting system during pre-retrofit condition, design, and development of the lighting control system and lastly analysis of the designed system in post-retrofit condition after installation.

\subsection{Initial study}

Initial study of energy consumption has been done by investigating the project site through energy audit at Faculty of Electronic Engineering Technology Complex, UniMAP. Overall, there are 12 buildings within the complex area. However, restrooms are located at selected buildings as shown in Table 1 where there are totally 30 restrooms available including 2 for disabled. There are 280 units of $2 \mathrm{ft}$ fluorescent tube lamps with $18 \mathrm{~W}$ rated power that are installed in all restrooms where the number of lamps for each restroom varies according to the restroom's area size and building location. In general, the utilization hours of the restrooms are for 10 hours from 8.00 am until 6.00 pm every day from Monday until Friday which is during office hours. Based on energy audit, it is observed that the timing operation is controlled by security or maintenance personnel hence sometimes the power supply is not turn-off and continuously operates for 24 hours. This situation has led to waste of electricity supply.

Table 1 No. of restrooms and lamps at faculty of electronic engineering technology complex

\begin{tabular}{llll}
\hline Building & No of restroom & No. of lamps & Total power $(\mathbf{k W})$ \\
\hline Building 1 & 4 & 56 & 1.008 \\
\hline Building 2 & 5 & 42 & 0.756 \\
\hline Building 5 & 7 & 62 & 1.116 \\
\hline Building 7 & 4 & 40 & 0.720 \\
\hline Building 9 & 6 & 60 & 1.080 \\
\hline Building 12 & 4 & 20 & 0.360 \\
\hline
\end{tabular}

\subsection{Field data measurement}

The field data measurement has been carried out to investigate the actual daily energy profile of the restrooms. In addition, the contribution of each building's restroom to the total power consumption of the restroom within the complex could also be identified. These data are essential prior starting any energy saving solution. The PEL103 Power and Energy Logger device is used for conducting energy studies and data logging for this project. It has been installed at each building's switch board room within the complex. All electrical safety precautions and procedures have been followed prior to this measurement.

The recorded daily energy profile for restrooms in Building 2 is shown in Figure 1. The result showed the loads are switched-on around 8:00 AM and remains in operation until it been switched off around 6:00 PM. From this trend, it can be concluded that there is no energy conservation activity been implemented. In addition, based on observation the restrooms are not used all the time where sometimes there is a long interval before somebody reused is again. Hence, this is an opportunity to conserve energy during the interval of unused time if the lamps could be turned off.

Based on the recorded data, the total energy consumption for all restrooms within the complex is $50.4 \mathrm{kWh}$ per day. If university operates 5 days pe week and 48 weeks per year, then the annual energy consumption for all restrooms is estimated to be $12096 \mathrm{kWh}$. This amount of energy is equivalent to RM 4415 of electricity bill at rated tariff of RM 0.365 per kWh.

In addition, the contribution of each building's energy consumption at Faculty of Electronic Engineering Technology also have been identified. 
As shown in Figure 2, restrooms at Building 5 and Building 9 consumed the highest amount of energy with $22.1 \%$ and $21.4 \%$ respectively. This is due to the Building 5 dan Building 9 that have three floors compared to other buildings which are only 2 levels therefore many restrooms available. Moreover Building 1, Building 2 and Building 7 contributed $20.0 \%, 15.0 \%, 14.3 \%$ each while Building 12 consumed the least with only $7.1 \%$.

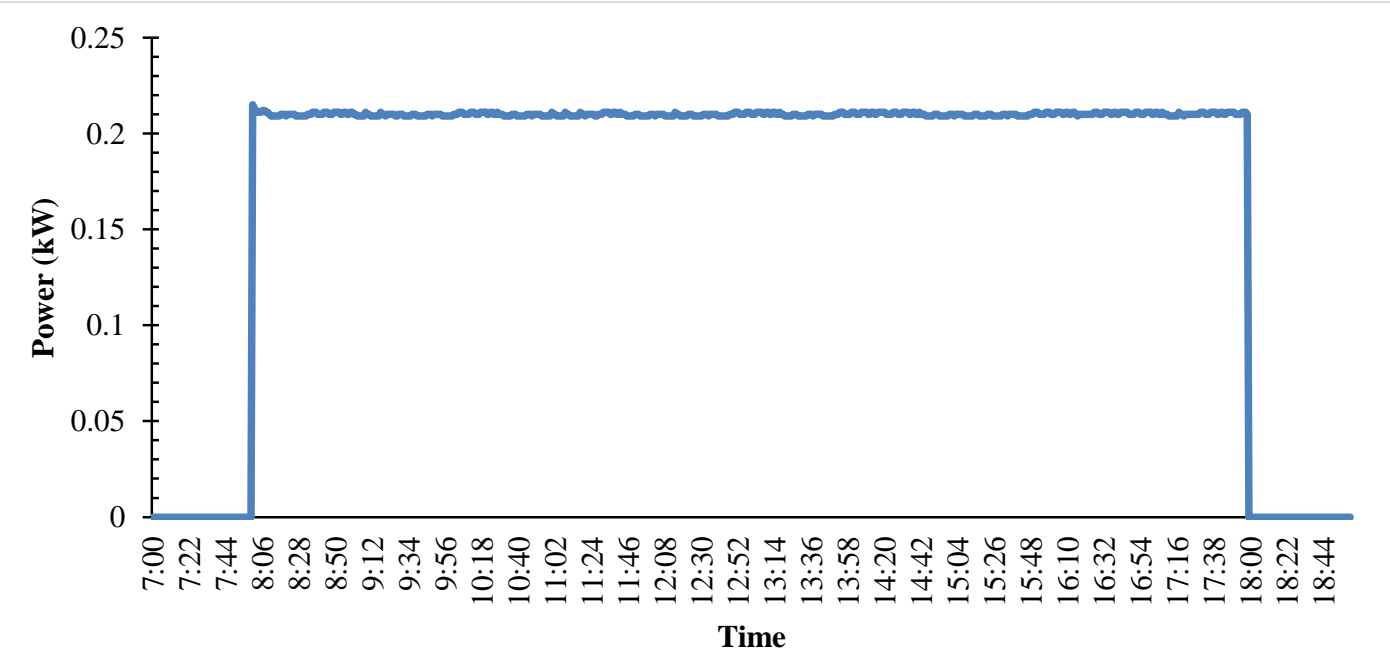

Figure 1 Daily energy profile for restrooms at Building 2 before retrofit

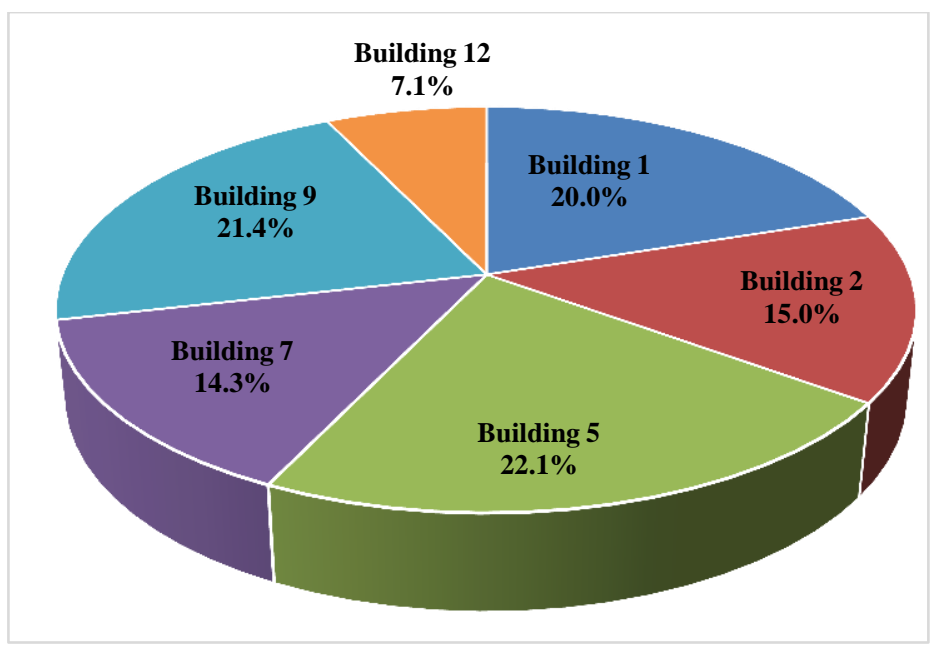

Figure 2 Percentage of energy consumption based on building

\subsection{Proposed energy saving solution}

The lighting system control based on zone is proposed as energy saving solution where the basic block diagram the proposed system is shown in Figure 3 below. The system consists of passive infrared (PIR) motion sensor as input while Arduino $\mathrm{UNO}$, an open-source microcontroller board is used as the main controller. A relay module, which is an electronically operated switch, is used as interface between the controller and lighting circuit. Depends on the number of outputs, four channels relay module is preferred with maximum voltage rating of $250 \mathrm{~V}$ 57 and maximum current rating up to $10 \mathrm{~A}$ for every relay. Each restroom will be divided into two zone areas where a PIR motion sensor will be installed at each zone to detect movement. The sensor could detect motion from all $360^{\circ}$ direction and up to $7 \mathrm{~m}$ distance by measuring changes in the infrared levels emitted by surrounding objects. Once movement is detected, the sensor will trigger signal to the microcontroller which then will activate the relay module to switch on the lamps. The sensitivity of the sensor and time delay could be adjusted according to the requirement. Each microcontroller can control up 
to four zones covering two restrooms that located nearby (usually side by side) where each zone is programmed to operate independently. The system is powered by a standard single phase $230 \mathrm{~V} 50 \mathrm{~Hz}$ voltage supply and consumed minimum amount of energy to power up the controller circuit.

Figure 4 shows the flowchart of the proposed system operation. The initial condition starts with switching on the power supply which will turn-on the lamps. The setting for the time delay is programmed to 10 minutes where if no movement detected within the interval, the microcontroller would send signal to the relay module to disconnect the power supply hence turning off the lamps. If movement detected within the 10 minutes interval, the lamps would continue to operate normally. This operating condition will continue until the power supply is switched-off manually. For beginning, the 10 minutes delay is selected based on observation, but it can be changed based on feedback from users such as to request longer interval. The fully developed system will be installed by retrofitting the existing wiring system.
This modification works will be done by certified electricians with permission from the university.

In general, energy saving from this project could be obtained from Equation (1):

$E S=E B R-E A R$

where $E S$ is energy saving in $\mathrm{kWh}, E B R$ is energy usage before retrofit in $\mathrm{kWh}$ and $E A R$ is energy usage after retrofit in $\mathrm{kWh}$. In addition, the cost saving could be calculated from Equation (2):

$C S=E S \times T R$

where $C S$ is cost saving in Ringgit Malaysia (RM), $E S$ is energy saving in $\mathrm{kWh}$ and $T R$ is tariff rate for the building in RM per kWh.

Currently, the university is using Tariff C1 (Medium Voltage Commercial) with tariff rate is at RM 0.365 per kWh.

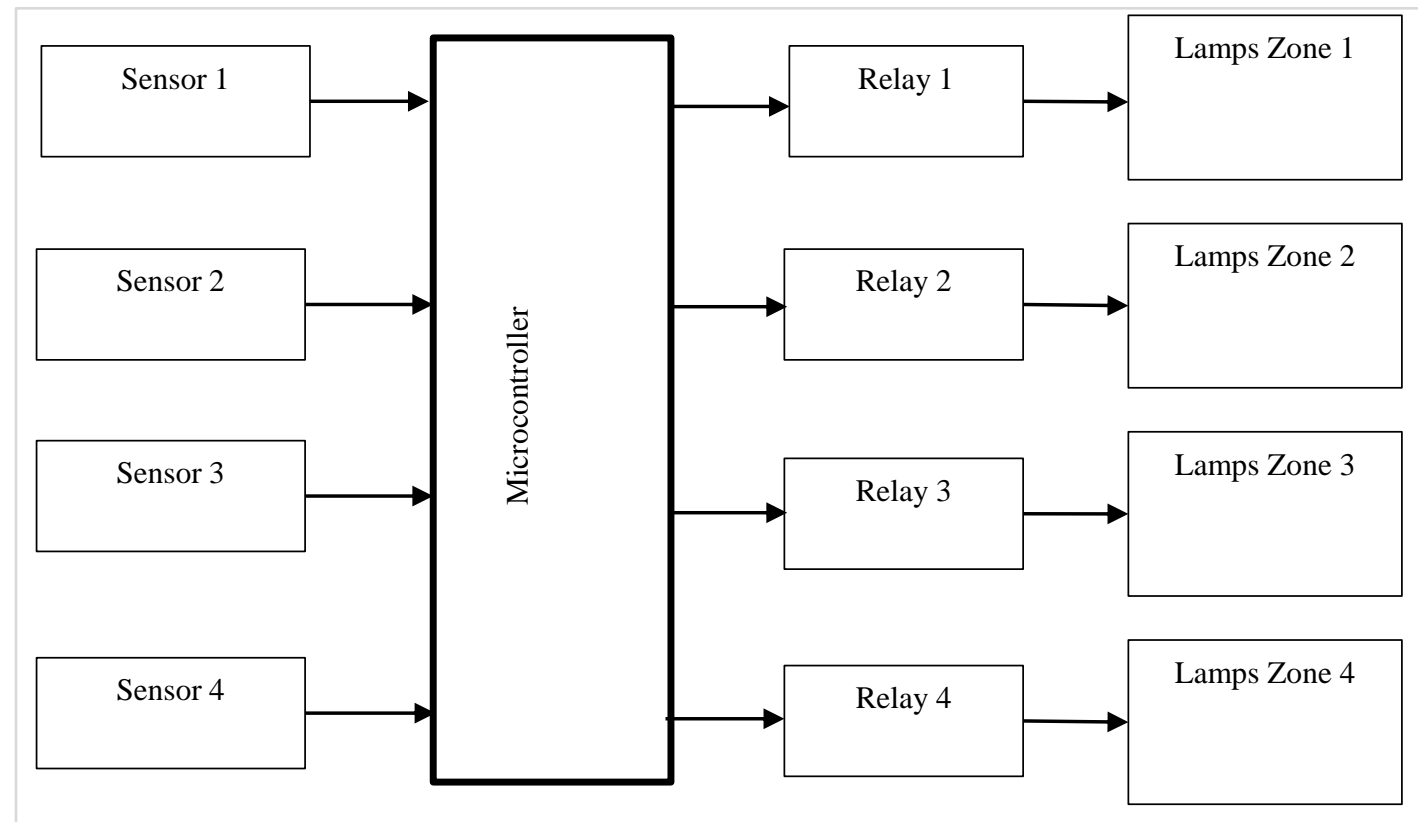

Figure 3 Basic block diagram of the proposed system 


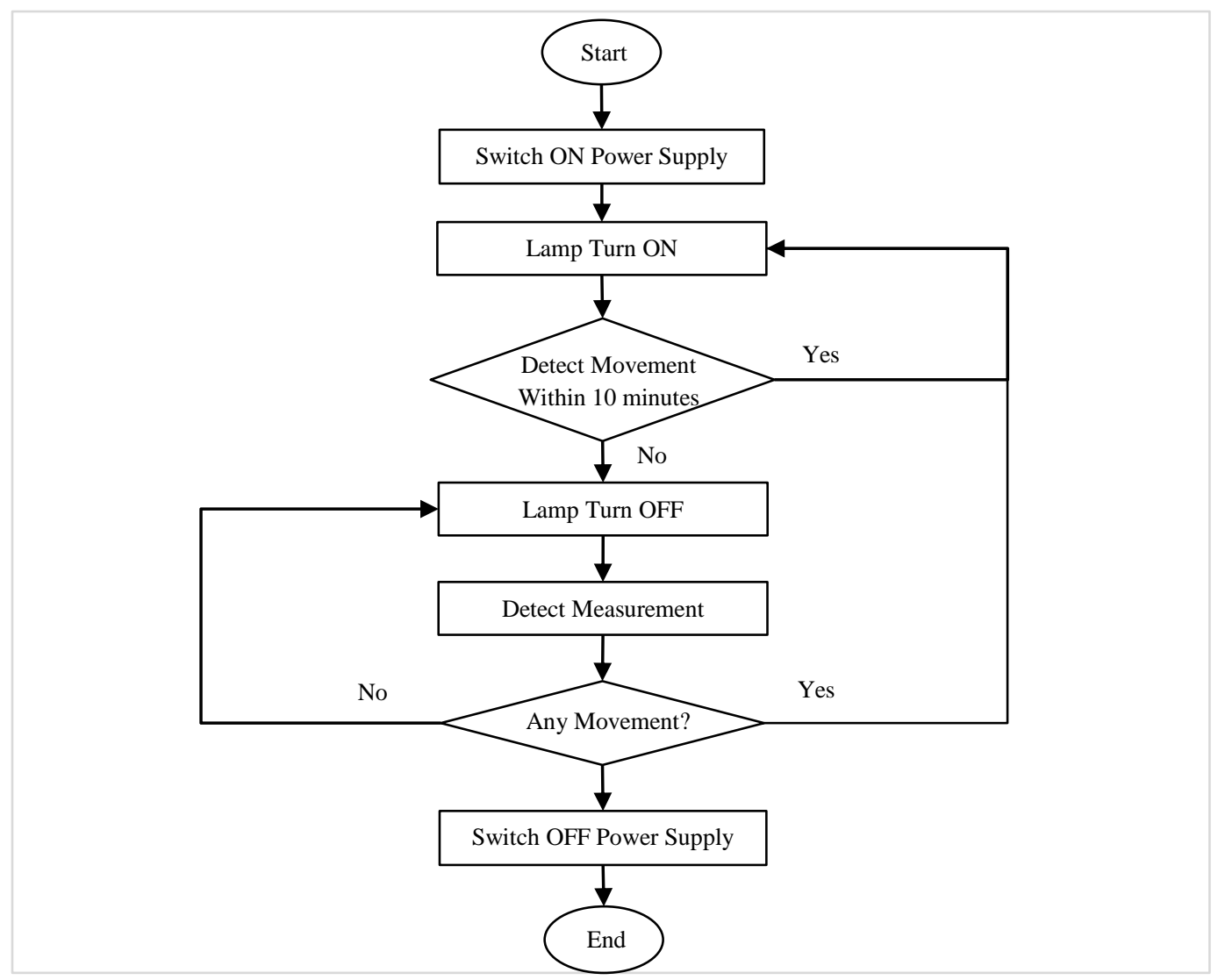

Figure 4 Flowchart of the proposed system operation

\section{Results and discussion}

The designed smart lighting control system has been successfully installed in all 30 restrooms at Faculty of Electronic Engineering Technology Complex. The number of motion sensors allocated for each building are shown in Table 2 where two sensors are installed at each restroom. For disabled restroom, only one sensor is installed because of its smaller area size. In total, 58 unit of motion sensors have been utilized for this project.

Similar to the pre-retrofit condition, PEL103 Power and Energy Logger device has been used to monitor the performance of the new designed system. The result shows significant drop in energy consumption for restrooms on every building. As shown in Figure 5 , the amount of daily energy consumed has drop drastically for every building after the retrofit. Generally, the amount of energy consumed per restroom is in the range between $20-30 \%$ per day only compared to the pre-retrofit condition. In average, the amount of energy consumed has significantly reduced to $22.5 \%$ per day hence resulted in $77.5 \%$ of saving in terms of electricity usage.
This result is due to the motion sensors operation that will only turn-on the lighting when it sensed the movement and will automatically turn-off the supply when no movement detected within interval period of 10 minutes as shown in Figure 6 where the power supply is observed to turn-on and turn-off repeatedly during daytime compared to the continuously turn-on during pre-retrofit condition. In addition, the 2 sensors used for each restroom have also increased the efficiency of the system where in certain times, only half of the lamps turned-on. This result has given tremendous benefits to the university operation. As shown in Figure 7 , the annual energy consumption specifically for restrooms has plunged to $2719 \mathrm{kWh}$ from $12906 \mathrm{kWh}$ before retrofit while the electricity cost at rated price of RM 0.365 per $\mathrm{kWh}$, has fall to less than RM 1000 per year after retrofit from RM 4415 previously. Overall, the university could save $9377 \mathrm{kWh}$ of electricity from this project and reduced RM 3423 of from electricity bill per annum. In addition, this project also contributes to the environmental sustainability where $9377 \mathrm{kWh}$ of electrical energy that has been successfully reduced is equivalent to $6508 \mathrm{~kg}$ of CO2 avoidance to the environment. 
Tunku Muhammad Nizar Tunku Mansur et al.

Table 2 No. of motion sensor installed according to building

\begin{tabular}{ll}
\hline Building & No. of motion sensor installed \\
\hline Building 1 & 8 \\
\hline Building 2 & 9 \\
\hline Building 5 & 13 \\
\hline Building 7 & 8 \\
\hline Building 9 & 12 \\
\hline Building 12 & 8 \\
\hline
\end{tabular}

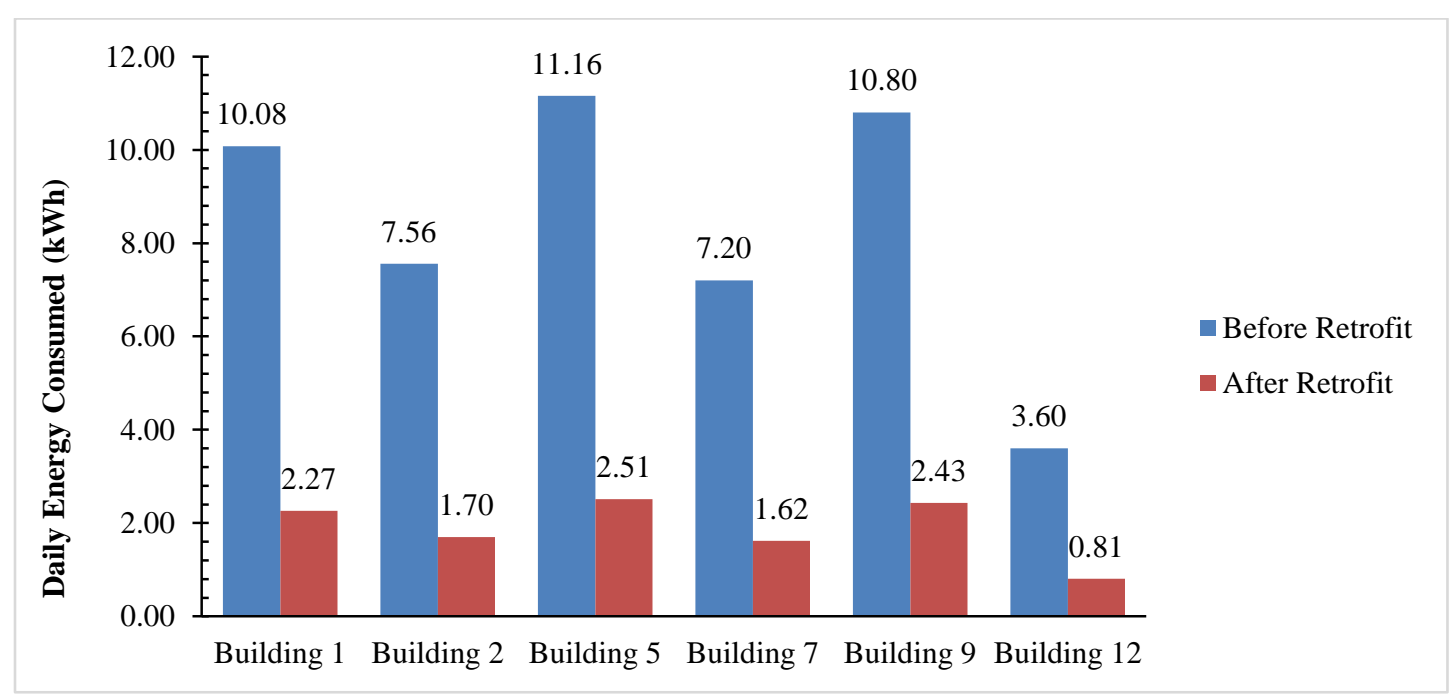

Figure 5 Comparison of energy consumption before and after retrofit for each building

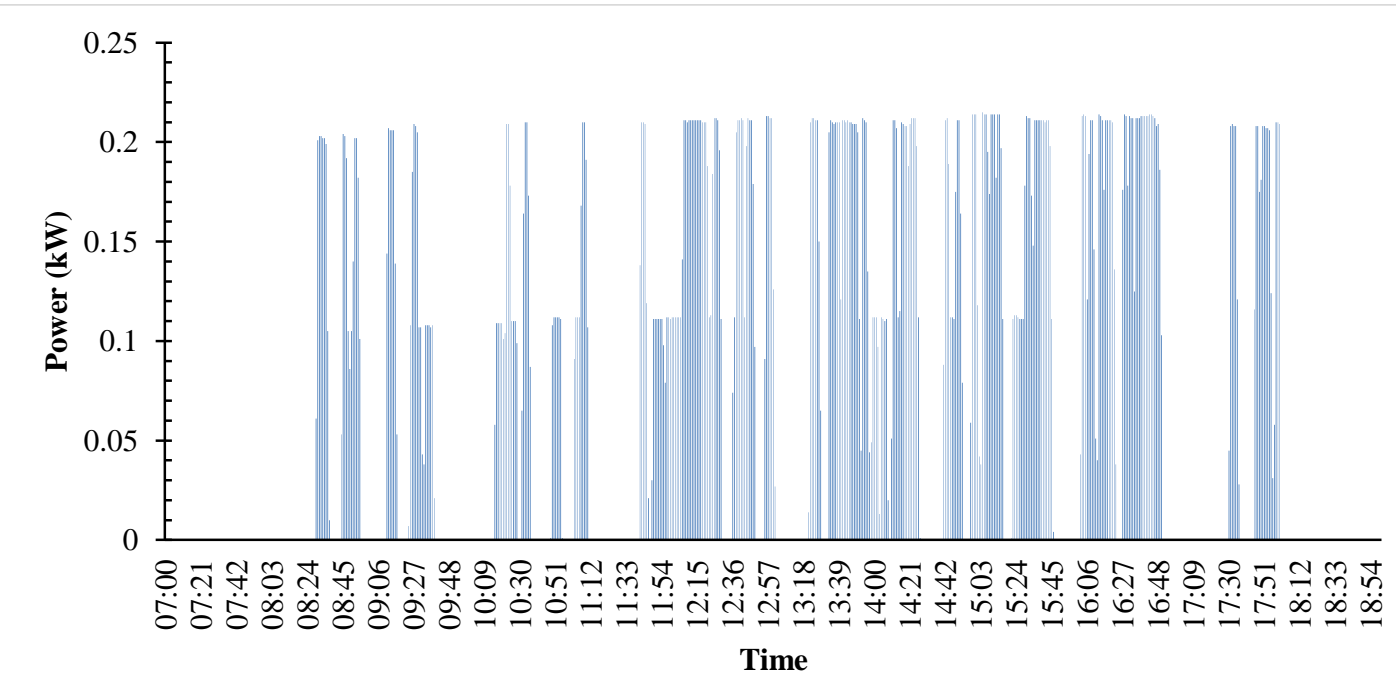

Figure 6 Daily energy profile for restrooms at building 2 after retrofit 


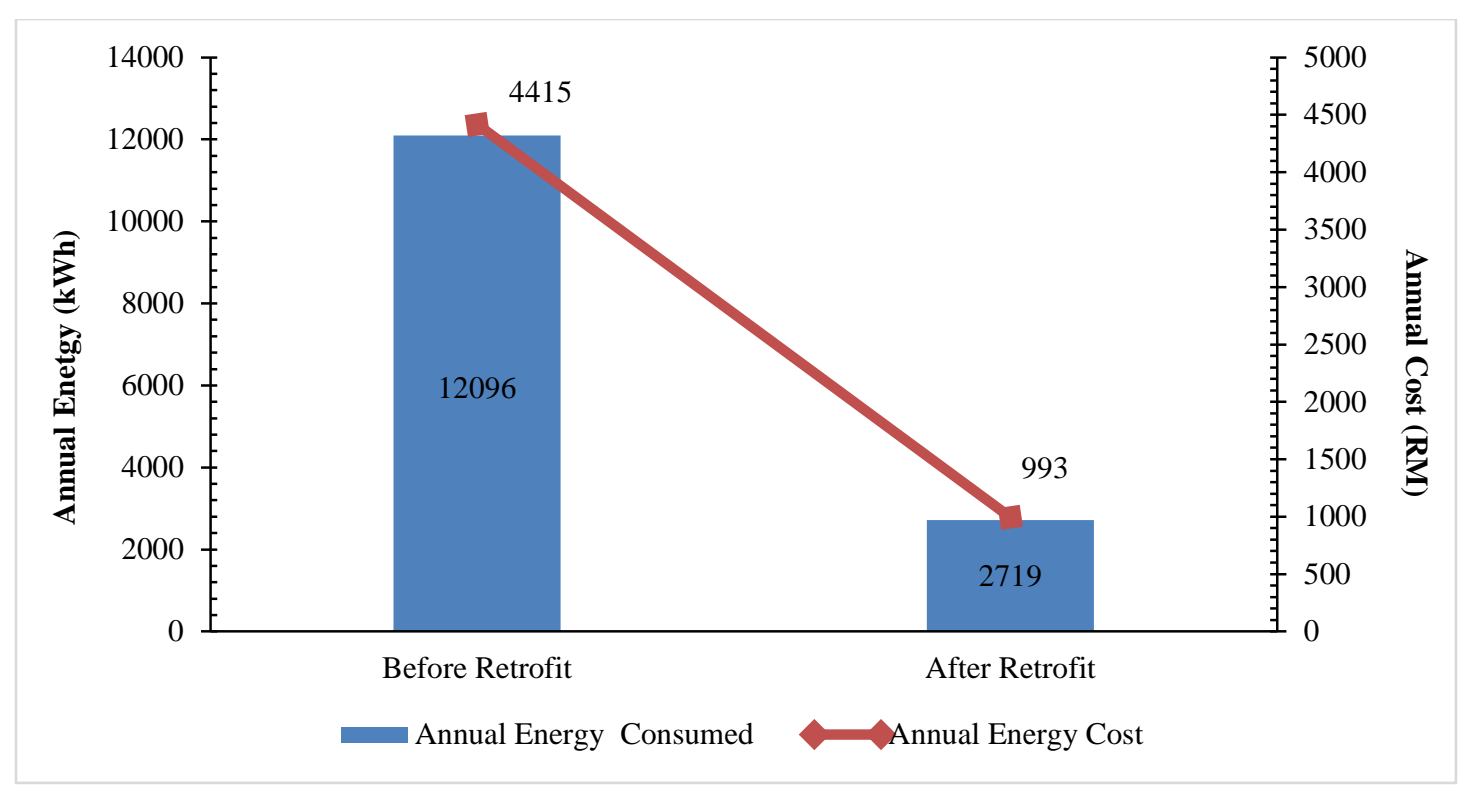

Figure 7 Comparison of annual energy and cost before and after retrofit

\subsection{Limitation of the approach}

This research work focused on the technical side of the designed system. However, the economic aspect of the system is not included in this study such as initial investments cost which cover the components and installation process, annual maintenance cost and lastly the lifetime of the system. The engineering economic tools such present worth analysis could be used to evaluate the viability of this project economically in addition to the technical aspect.

\section{Conclusion and future work}

The performance of smart lighting control system for restrooms has been presented in this paper. Overall, 58 motion sensors have been installed at 30 restrooms at Faculty of Electronic Engineering Technology Complex, University Malaysia Perlis. The result shows that in average $77.5 \%$ of reduction in energy consumption per day for each restroom. This situation has given tremendous benefits to the university operation where the university could save $9377 \mathrm{kWh}$ per year and reduced RM 3423 from electricity bill per annum. In addition, this project also contributes to the environmental sustainability where the amount of electrical energy that has been successfully reduced is equivalent to $6508 \mathrm{~kg}$ of $\mathrm{CO} 2$ avoidance to the environment.

In future, the implementation of this smart lighting control system could be extended to other facilities within the campus such as lecture halls and offices due to its ability to reduce electricity consumption. In addition, data logger module with Internet of Things 61
(IoT) capability could be added for real time data monitoring to enhance the features of the existing design framework.

\section{Acknowledgment}

The authors would like to acknowledge the support from the Internal Social Project Via Research (INSPIRE) Research Grant 2019 under a grant number of UniMAP/PPPI/9001-00584(1) from Universiti Malaysia Perlis.

\section{Conflicts of interest}

The authors have no conflicts of interest to declare.

\section{References}

[1] Mathur A, Muthukumaraswamy SA. On the enhancement of building energy conservation using energy auditing. In international conference on intelligent sustainable systems 2017 (pp. 720-4). IEEE.

[2] Light J. Energy usage profiling for green computing. In international conference on computing, communication and automation 2017 (pp. 1287-91). IEEE.

[3] Mansur TM, Baharudin NH, Ali R. Performance analysis of self-consumed solar PV system for a fully DC residential house. Indonesian Journal of Electrical Engineering and Computer Science. 2017; 8(2):391-8.

[4] Faghihi V, Hessami AR, Ford DN. Sustainable campus improvement program design using energy efficiency and conservation. Journal of Cleaner Production. 2015; 107:400-9.

[5] Kartikasari FD, Tarigan E, Fransiscus Y, Lidyawati T. Energy saving measures and potential of energy efficiency at the university of Surabaya, based on EDGE simulation. In international conference on 
Tunku Muhammad Nizar Tunku Mansur et al.

information technology, computer, and electrical engineering 2018 (pp. 89-92). IEEE.

[6] Cho HM, Yun BY, Yang S, Wi S, Chang SJ, Kim S. Optimal energy retrofit plan for conservation and sustainable use of historic campus building: case of cultural property building. Applied Energy. 2020.

[7] Hamdaoui S, Mahdaoui M, Allouhi A, El Alaiji R, Kousksou T, El Bouardi A. Energy demand and environmental impact of various construction scenarios of an office building in Morocco. Journal of Cleaner Production. 2018; 188:113-24.

[8] Latif MH, Ahmed T, Khalid W, Anis M, Mahmood T. Energy audit, retrofitting and solarization in educational institutes of Pakistan: an effective approach towards energy conservation. In international conference on engineering and emerging technologies 2019 (pp. 1-6). IEEE.

[9] Martirano L. Lighting systems to save energy in educational classrooms. In international conference on environment and electrical engineering 2011 (pp. 1-5). IEEE.

[10] Lai X, Dai M, Rameezdeen R. Energy saving based lighting system optimization and smart control solutions for rail transportation: evidence from China. Results in Engineering. 2020.

[11] Berde PA, Bhavani RG. Investigation for reducing energy consumption for a university campus in Dubai using automation. In recent advances in intelligent computational systems 2015 (pp. 358-63). IEEE.

[12] Wagiman KR, Abdullah MN, Hassan MY, Radzi NH. A review on sensing-based strategies of interior lighting control system and their performance in commercial buildings. Indonesian Journal of Electrical Engineering and Computer Science. 2019; 16(1): 20815 .

[13] Abdullah A, Yusoff SH, Zaini SA, Midi NS, Mohamad SY. Energy efficient smart street light for smart city using sensors and controller. Bulletin of Electrical Engineering and Informatics. 2019; 8(2):558-68.

[14] Verma N, Jain A. Optimized automatic lighting control in a hotel building for energy efficiency. In international conference on power energy, environment and intelligent control 2018 (pp. 168-72). IEEE.

[15] Bannamas S, Jirapong P. An intelligent lighting energy management system for commercial and residential buildings. In innovative smart grid technologies-Asia (ISGT ASIA) 2015 (pp. 1-6). IEEE.

[16] Kaneko Y, Matsushita M, Kitagami S, Kiyohara R. An energy-saving office lighting control system linked to employee's entry/exist. In global conference on consumer electronics 2013 (pp. 440-4). IEEE.
[17] Ul Haq MA, Hassan MY, Abdullah H, Rahman HA, Abdullah MP, Hussin F, et al. A review on lighting control technologies in commercial buildings, their performance and affecting factors. Renewable and Sustainable Energy Reviews. 2014; 33:268-79.

[18] Zakaria NA, Hassan M Y, Abdullah H, Abdullah M P, Hussin F, Hussin S M, et al. Energy efficiency index by considering number of occupants: a study on the lecture rooms in a university building. Indonesian Journal of Electrical Engineering and Computer Science. 2019; 15; (3):1154-60.

[19] Bulan LA, Maderazo LR, Asi PB. Design and development of microcontroller-based air conditioning units controller as input to energy conservation for university of Batangas. International Journal of Advanced Trends in Computer Science and Engineering. 2019; 8(4):1020-5.

[20] Mansur TM, Baharudin NH, Ali R. A comparative study for different sizing of solar PV system under net energy metering scheme at university buildings. Bulletin of Electrical Engineering and Informatics. 2018; 7(3):450-7.

[21] Mulla F, Tambakad SS, Patil RG. Energy conservation through lighting audit-a case study of hostel building. In 3rd international conference on recent developments in control, automation \& power engineering 2019 (pp. 191-6). IEEE.

[22] Gorgulu S, Kocabey S. An energy saving potential analysis of lighting retrofit scenarios in outdoor lighting systems: a case study for a university campus. Journal of Cleaner Production. 2020.

[23] Neardey M, Aminudin E, Chung LP, Zin RM, Zakaria $\mathrm{R}$, Wahid CC, et al. Simulation on lighting energy consumption based on building information modelling for energy efficiency at highway rest and service areas Malaysia. In IOP conference series: materials science and engineering 2020 (pp.1-10). IOP Publishing.

[24] Ayan O, Turkay B. IoT-based energy efficiency in smart homes by smart lighting solutions. In international symposium on electrical apparatus \& technologies 2020 (pp. 1-5). IEEE.

[25] Shafei M, Tawfik M, Khalil D. Improving energy efficiency in egyptian airports: a case study of sharmelshiekh airport. In international middle east power systems conference 2019 (pp. 289-94). IEEE.

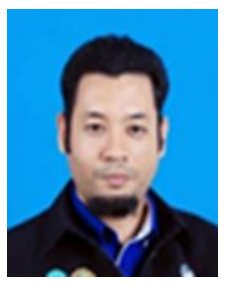

Tunku Muhammad Nizar Tunku Mansur received his B.Eng. (Electrical) from PETRONAS University of Technology, Malaysia in 2003 and M.Eng.Sc. (Electrical) from Curtin University of Technology, Australia in 2009. Currently working as Senior Lecturer at Universiti Malaysia Perlis and also as Deputy Director at Centre of Sustainable Campus and Energy Management, Universiti Malaysia Perlis. His research interests include Renewable Energy, LVDC, and Energy Management.

Email: tunkunizar@unimap.edu.my 


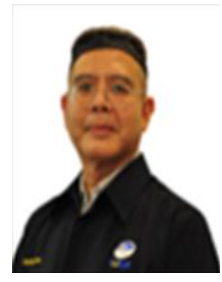

Rosnazri Ali received his B.Eng. (Electrical) from Royal Melbourne Institute of Technology in 1988, M.Sc. (Electrical) from Universiti Sains Malaysia in 2008 and PhD (Electrical) from Universiti Malaysia Perlis in 2014. Currently working as Associate Professor at Universiti Malaysia Perlis and research fellow at Centre of Excellence for Renewable Energy (CERE), Universiti Malaysia Perlis. His major interest of research includes Renewable Energy, Energy Efficient Systems and Power Electronics.

Email: rosnazri@unimap.edu.my

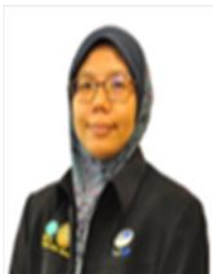

Nor Hanisah Baharudin received the B.E., M.Eng.Sc. and Ph.D. degree in electrical engineering from PETRONAS University of Technology, Malaysia, Curtin University of Technology, Australia and Universiti Malaysia Perlis in 2005, 2009 and 2018 respectively. She is currently working as senior lecturer at Universiti Malaysia Perlis and research fellow at Centre of Excellence for Renewable Energy (CERE), Universiti Malaysia Perlis. Her research interests include Renewable Energy, Energy Efficiency, Power Quality, and Design of Custom Power Devices.

Email: norhanisah@unimap.edu.my

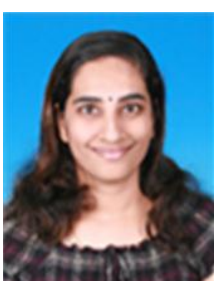

Kumuthawathe Ananda-Rao received the B.Eng. and Ph.D. degree in electrical engineering from Universiti Malaysia Perlis in 2008 and 2018 respectively. She is currently working as senior lecturer at Universiti Malaysia Perlis. Her research interests include Renewable Energy, Energy Storage System and Power Electronics.

Email: kumuthawathe@unimap.edu.my 